\title{
Psychological correlates of COVID-19 conspiracy beliefs and preventive measures: Evidence from Turkey
}

\author{
Sinan Alper ${ }^{1}$ (D) Fatih Bayrak ${ }^{2} \cdot$ Onurcan Yilmaz $^{3}$ \\ Published online: 29 June 2020 \\ (C) Springer Science+Business Media, LLC, part of Springer Nature 2020
}

\begin{abstract}
COVID-19 pandemic has led to popular conspiracy theories regarding its origins and widespread concern over the level of compliance with preventive measures. In the current preregistered research, we recruited 1088 Turkish participants and investigated (a) individual differences associated with COVID-19 conspiracy beliefs; (b) whether such conspiracy beliefs are related to the level of preventive measures; and (c) other individual differences that might be related to the preventive measures. Higher faith in intuition, uncertainty avoidance, impulsivity, generic conspiracy beliefs, religiosity, and right-wing ideology, and a lower level of cognitive reflection were associated with a higher level of belief in COVID-19 conspiracy theories. There was no association between COVID-19 conspiracy beliefs and preventive measures while perceived risk was positively and impulsivity negatively correlated with preventive measures. We discuss the implications and directions for future research.
\end{abstract}

Keywords COVID-19 $\cdot$ Conspiracy $\cdot$ Individual differences $\cdot$ Pandemic $\cdot$ Preventive

As of April 2020, Coronavirus Disease 2019 (COVID-19) pandemic has not only resulted in over 2 million cases and 130,000 deaths (World Health Organization 2020a), but also led to popular conspiracy theories regarding its origins. In the current preregistered research, we recruited a large sample $(N=1088)$ from an underrepresented society in psychology literature, Turkey, which also happens to be the seventh country in the world with the most COVID-19 cases, as of April 2020. We aimed to investigate (1) individual differences that might be associated with COVID-19 conspiracy beliefs; (2) whether COVID-19 conspiracy beliefs were related to the preventive measures (e.g., social distancing, wearing masks, etc.); and (3) how individual differences in several psychological variables including risk perception, uncertainty avoidance, and intuitive thinking style were related to the level of preventive measures.

Electronic supplementary material The online version of this article (https://doi.org/10.1007/s12144-020-00903-0) contains supplementary material, which is available to authorized users.

\section{Sinan Alper}

sinan.alper@yasar.edu.tr

1 Department of Psychology, Yasar University, Izmir, Turkey

2 Department of Psychology, Baskent University, Ankara, Turkey

3 Department of Psychology, Kadir Has University, Istanbul, Turkey

\section{Predictors of COVID-19 Conspiracy Beliefs}

Conspiracy theories are unwarranted beliefs that certain events are planned and carried out by secret, malevolent, and powerful organizations (Douglas and Sutton 2015; Swami and Furnham 2014). The desire to understand and control events around can be met through conspiracy theories, and so it provides satisfaction to epistemic, existential, and social motives (Douglas et al. 2017). Epistemic motives refer to desire for understanding the world, accuracy in the environment, and subjective certainty; existential motives characterized with a need for control and security; and social motives describe a desire to maintain a positive image of own self or group (Jost et al. 2008). However, studies show that this taxonomy does not fully explain conspiracy beliefs and their consequences (Douglas et al. 2017). It is seen that the conspiracy belief interacts with several factors such as personality, thinking styles, ideology, and circumstances.

There is extensive literature indicating that belief in conspiracy theories is based on individual differences in thinking styles, cognitive ability, and motivation of critical thinking (Douglas et al. 2017). For example, sense-making motivation is the strongest predictor of conspiracy beliefs (van Prooijen and van Dijk 2014). The need for closure is also associated with believing conspiracy theories (Leman and Cinnirella 2013; Marchlewska et al. 2018). Studies showed that individuals who believe in any conspiracy theory tend to believe in 
another conspiracy theory even when they are unrelated (Swami et al. 2010; Wood et al. 2012). Therefore, a general tendency to believe in conspiracy theories would be expected to be positively associated with COVID-19 conspiracy beliefs.

Besides, two important predictors of believing in conspiracy theories are feeling of control and uncertainty. Subjective uncertainty makes conspiracy theories seem more plausible and increases the tendency to believe them (van Prooijen and Jostmann 2013). A related factor, lack of control has also a similar effect: Lacking a sense of control is positively associated with having a conspiracy mentality (Bruder et al. 2013) and perceiving patterns in random stimuli (van Harreveld et al. 2014; Whitson and Galinsky 2008).

People with high levels of uncertainty avoidance would be less tolerant of the ambiguities surrounding the pandemic (e.g., the exact source of the disease, debates on how it can be cured, etc.). Such uncertainty, and the anxiety it produces, would render people with high uncertainty avoidance to be more prone to believe in conspiracy theories that provide "more clear", and yet incorrect, explanations. Since perceived stress and stressful life events such as illness and bereavement predict belief in conspiracy theories (Swami et al. 2016), the perceived risk of getting infected by COVID-19 could also be an important predictor. In other words, as people with a higher perception of risk would lack the sense of control over the situation, it might be related to believing in COVID-19 conspiracy theories, as well as the level of compliance with the preventive measures, suggested to minimize the risk of infection. Thus, it could be argued that uncertainty avoidance and the perceived risk of getting infected by COVID-19 would predict belief in COVID-19 conspiracy theories.

Individuals who perform better on cognitive reflection test (Frederick 2005; which indicates more analytical, as opposed to intuitive, thinking) are less likely to believe in conspiracy theories (Pennycook et al. 2015; Swami et al. 2014), and they are better at detecting fake news (Bronstein et al. 2019; Pennycook and Rand 2019). Furthermore, in a recent study, Stanley et al. (2020) found that individuals who perform worse on the cognitive reflection test are more likely to believe that the COVID-19 is a hoax. Based on these findings, we expected that more intuitive thinkers would be more likely to believe in COVID-19 conspiracy theories. Being closely associated with a lack of elaboration (e.g., Bakhshani 2014), impulsivity was also considered as a potential factor that might be associated with COVID-19 conspiracy beliefs.

Ideology and religiosity are also important predictors of belief in conspiracy theories. It was found that conservatives are more likely to believe in conspiracy theories (Pasek et al. 2015; Swami 2012; Swami et al. 2012). Religiosity is also positively associated with conspiracy beliefs (Douglas et al. 2016; Franks et al. 2013; Newheiser et al. 2011). Thus, we argue that political conservatism and religiosity would be positively associated with beliefs in COVID-19 conspiracy theories.

Although there is an abundance of research on the predictors of conspiracy beliefs, its social consequences are less known (Jolley et al. 2020). Studies show that conspiracy beliefs are potentially harmful in several domains (Douglas and Sutton 2018). In these few studies, conspiracy beliefs have been found to be predictors of prejudice towards outgroups (Jolley et al. 2020; Imhoff and Bruder 2014), intergroup conflict (Bilewicz et al. 2013), being less engaged in politics and voting (Jolley and Douglas 2014), decreased organizational commitment (van Prooijen and de Vries 2016), everyday crime (Jolley et al. 2019), negative attitudes about global warming (Douglas and Sutton 2004), and health-related behaviors (Jolley and Douglas 2014).

\section{COVID-19 Conspiracy Beliefs and Preventive Measures}

Previous studies showed that there is a negative relationship between believing in conspiracy theories and health-related measures (for a systematic review, see Goreis and Voracek 2019; Jolley and Douglas 2014; Oliver and Wood 2014). For example, individuals who believe in conspiracy theories show lower vaccination intentions, getting annual checkups, and higher rejection of modern medicine (Jolley and Douglas 2014; Oliver and Wood 2014; Lewandowsky et al. 2013). Conspiracy beliefs are also related to preventive measures towards sexually transmitted infections. Believing conspiracy theories about HIV, decreases prevention measures towards it (Bogart and Thorburn 2006) and increases risky sexual behaviors (Gaston and Alleyne-Green 2013). Contraceptive behaviors are also negatively affected by conspiracy theories. An increase in believing conspiracy theories about pregnancy is associated with a decrease in pregnancy prevention behaviors and intentions (Bird and Bogart 2005).

In a recent study, Plohl and Musil (2020) showed that believing generic conspiracist beliefs indirectly predicts compliance with COVID-19 prevention guidelines through trust in science. Individuals who trust more in science implement more preventive behaviors during the COVID-19 outbreak and this relationship is mediated by believing in conspiracy theories (Plohl and Musil 2020). However, the evidence is scarce on the association between believing in COVID-19 conspiracies and preventive behaviors especially in underrepresented and non-WEIRD societies (Henrich et al. 2010). Therefore, one of the goals of this study is to explore this association in Turkey, a non-WEIRD society. 


\section{Predictors of Preventive Measures}

World Health Organization (2020b) has identified various preventive behaviors against COVID-19 (e.g., handwashing, avoid touching eyes, and social distancing). Although these preventive behaviors are crucial to minimizing the spread of the disease, some individuals do not implement them. Certain individual differences, including the ones explained above, might be related to these preventive behaviors. One such factor might be risk perception (Cameron and Diefenbach 2001; McCaul et al. 2003). In a study on the SARS epidemic, it was found that individuals who perceive greater risk about the outbreak were more likely to implement precautionary measures against the infection (Leung et al. 2004). However, in early studies on COVID-19, there were some mixed findings on this relationship. It was found that individuals who fear more about COVID-19 report exhibiting more public health compliance behaviors such as hand washing and social distancing (Harper et al. 2020). However, according to the results of a study in Wuhan, China (where the COVID-19 pandemic started), the risk perception was found to be negatively related to preventive behaviors (Qian et al. 2020).

Impulsivity might be another factor in predicting the level of preventive behaviors. Impulsivity is a multi-dimensional feature that expresses unplanned, impatient, and careless behaviors regardless of considering consequences with fast processing of information and poor inhibitory control (e.g., Patton et al. 1995). It is associated with risky behaviors with harmful consequences for health (e.g., Granö et al. 2004).

Thus, previous literature suggests that individual differences in the variables summarized above might play a role in preventive behaviors. We aimed to explore these individual differences that might be related to the level of compliance with the preventive measures taken against COVID-19. We were also interested in the potential association between COVID-19 conspiracy beliefs and preventive behaviors to have an understanding of the potential health-related consequences of widely held conspiracy beliefs.

\section{Overview of the Current Research}

Based on the previous literature, we hypothesized that (1) higher scores in faith in intuition, generic conspiracy beliefs, uncertainty avoidance, ${ }^{1}$ impulsiveness, religiosity, and rightwing political orientation and a lower score in cognitive reflection would be associated with higher scores in belief in COVID-19 conspiracies; and (2) belief in COVID-19 conspiracies would be related to the level of preventive behaviors. We also explored the associations between our variables and

\footnotetext{
${ }^{1}$ We unintentionally omitted uncertainty avoidance in the preregistration form, although it was included in our hypothesis.
}

preventive behavioral intentions. We preregistered our hypotheses, stopping rule for data collection, and data analytical strategy before data collection (https://osf.io/kp8md/?view only $=81$ ec63a0efd $1443 \mathrm{da} 8 \mathrm{fa} 82399 \mathrm{e} 388 \mathrm{f3d}){ }^{2}$

\section{Method}

Data and materials are available online (https://osf.io/umt $4 \mathrm{~d} /$ ? view_only=a19fbe8299a84f5f9e7342591f21077a).

\section{Participants}

Participants were recruited via Facebook and Twitter in exchange for gift draws. We have announced the link to the online study on these social media platforms, and, as stated in the preregistration, we stopped data collection after seven days. A total of 1133 participants completed all measures of the study. We excluded 45 participants who either (a) failed the attention check question which explicitly asked to choose one of the options; (b) took a very long ( $z$ for the duration for completion is larger than 3 ), or (c) took a very short time ( $z$ is smaller than -3). All exclusion criteria were specified in the preregistration form. The resulting sample consisted of 1088 participants (790 females, 291 males, 7 responded as "other"; $\left.M_{\text {age }}=31.02, S D=39.43\right)$.

\section{Measures}

The order of measures, except for demographic form, was randomized for each participant. The demographic form appeared in the last section of the survey.

Belief in COVID-19 Conspiracy Theories As a measure of how much they were eager to believe in conspiracy theories regarding COVID-19, we developed a 2-item scale where participants were asked to report how much they agree $(1=$ strongly disagree, 7 = strongly agree) with the followings: "Coronavirus was developed and spread around the world by certain people for their own purposes" and "There is no intentional plan of a person or a group behind the spreading of coronavirus around the world" (reverse item). Cronbach's alpha for the two items was .81.

Generic Conspiracist Beliefs We measured the general tendency to believe in conspiracy theories that are unrelated to COVID-19 by using the 15-item Generic Conspiracist Beliefs Scale (Brotherton et al. 2013). An example item was

\footnotetext{
${ }^{2}$ We also had a non-directional preregistered hypothesis that individual differences might moderate the association between COVID-19 conspiracy theories and preventive measures. As these analyses are not central to the current research, we report those findings in the Online Supplementary Material (SM).
} 
"Secret organizations communicate with extraterrestrials, but keep this fact from the public". We translated the items into Turkish and a 5-point response scale $(1=$ definitely not true, $5=$ definitely true) was used. Cronbach's alpha was found to be .90 .

Preventive Measures We developed 7 items to measure how much participants abided with the suggested preventive measures that would minimize the risk of infection. An example item was "After I spent time outside, I clean my hands with soap or hand sanitizer". A 7-point response scale $(1=$ strongly disagree, $7=$ strongly agree) was used. Cronbach's alpha was .65 .

Faith in Intuition Faith in intuition was measured using Pacini and Epstein's (1999) 11-item scale. The scale measures to what extent someone trusts his/her instincts and hunches and it was previously adapted to Turkish (Türk and Artar 2014). An example item was "I believe in trusting my hunches". A 7-point response scale $(1=$ strongly disagree, $7=$ strongly agree) was used. Cronbach's alpha was found to be .91 .

Cognitive Reflection Cognitive reflection test (CRT) measures intuitive versus analytical thinking, using 3 mathematical questions for which the intuitive responses are incorrect (Frederick 2005). Turkish version of the test has been previously used (e.g., Yilmaz and Saribay 2016). We first cleaned the data by converting any non-numerical responses to numerical and standardizing the responses (for example, some participants responded as 0,05 Turkish liras whereas others wrote 5 kurus, the equivalent of a cent, which is essentially the same answers). Incorrect answers were coded as 0 while correct ones as 1; then the scores were summed. A higher score indicates more analytical thinking. Cronbach's alpha was .63.

Impulsivity To measure impulsivity in thinking and behavior, we used the 15-item Turkish version of the Barratt Impulsivity Scale-11 (Güleç et al. 2008; Patton et al. 1995). An example item was "I say things without thinking". A 4-point ( $1=$ never, $4=$ always) response scale was used. The items of "I change hobbies" and "I think about the future" (reverse item) had item-total correlations of less than .30 and thus were removed. The remaining 13 items had a Cronbach's alpha of .80 .

Uncertainty Avoidance We used 12-item uncertainty avoidance scale which was developed by Carleton et al. (2007) and adapted to Turkish by Sarıçam et al. (2014) to measure how much participants found uncertain situations as uncomfortable. An example item was "Unforeseen events upset me greatly". A 5-point response scale $(1=$ not at all characteristic of me, $5=$ entirely characteristic of me) was used. Cronbach's alpha was .90 .
Perceived Risk Oh et al. (2020) used a 4-item scale to measure perceived risk in the context of the MERS outbreak in 2015. We translated it to Turkish and re-worded the items to adapt to the COVID-19 context. An example item was "I will probably be infected by coronavirus". A 7-point response scale $(1=$ strongly disagree, $7=$ strongly agree) was used. Cronbach's alpha was .56.

Demographic Form At the end of the study, participants filled out a socio-demographic form including questions on age, sex (male, female, or other), education level (ranging from primary school to $\mathrm{PhD}$ on a 7-point scale), perceived socioeconomic status (measured on a socioeconomic status ladder; ranging from 1 , the bottom of the ladder, to 10 , the top of the ladder $)$, ideology $(1=e x$ tremely leftist, $7=$ extremely rightist $)$, religiosity $(1=$ not religious at all, $7=$ very religious) (see SM for detailed analyses on the socio-demographic differences).

\section{Results}

\section{Psychological Correlates of COVID-19 Conspiracy Beliefs}

Belief in COVID-19 conspiracy theories had a positive correlation with faith in intuition, $r=.206, p<.001$, and negative correlation with CRT, $r=-.178, p<.001$, and these suggested that more intuitive (as opposed to analytical) thinkers were more likely to believe that there is a conspiracy behind COVID-19 pandemic, as hypothesized (see Table 1).

Another psychological trait that is associated with COVID-19 conspiracy beliefs is uncertainty avoidance. Those who are less tolerant of uncertain situations were more likely to believe in conspiracy theories on COVID$19, r=-.178, p<.001$. Impulsivity, $r=.062, p=.042$, and perceived risk, $r=-.066, p=.029$, were also correlated with COVID-19 conspiracy beliefs, but the magnitudes of correlations are very weak. As hypothesized, COVID19 conspiracy beliefs were closely related to generic conspiracist beliefs, $r=.513, p<.001$.

As for sociodemographic differences, more religious, $r=.231, p<.001$, and more politically rightist, $r=.165$, $p<.001$, participants were more likely to believe in COVID19 conspiracies, as expected.

We expected that higher faith in intuition, uncertainty avoidance, impulsivity, generic conspiracy beliefs, religiosity, and right-wing ideology, and a lower level of cognitive reflection would be associated with a higher level of belief in COVID-19 conspiracy theories in Turkey. All of these hypotheses were supported. 


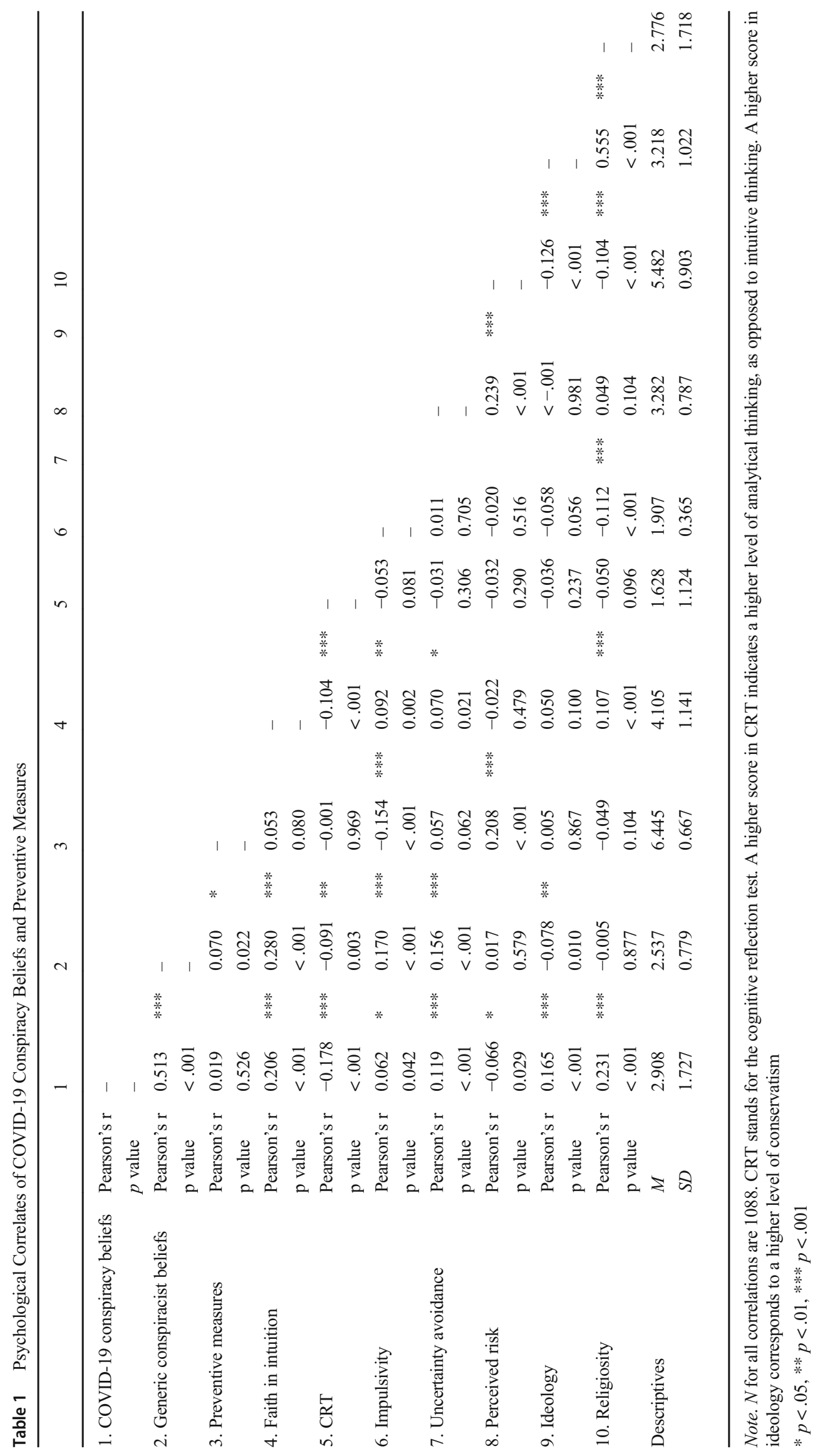




\section{Psychological Correlates of Preventive Measures}

COVID-19 conspiracy beliefs were unrelated to the level of preventive measures taken to minimize the risk of infection, $r=.019, p=.526$. Bayesian correlation analysis also revealed support for the null hypothesis $\left(\mathrm{BF}_{01}=\right.$ 21.529). Generic conspiracist beliefs, on the other hand, had a significant but very small positive correlation with preventive measure, $r=.070, p=.022$. Thus, there was no conclusive evidence to suggest any meaningful relationship between conspiracy beliefs and COVID-19-related preventive measures in Turkey.

The results also showed that more impulsive participants were less likely to take preventive measures, $r=$ $-.154, p<.001$. Since the impulsivity corresponds to a lack of elaboration before performing the behavior (Bakhshani 2014), such a result would be expected. Also, those with a higher perception of risk were more likely to take preventive measures, $r=.208, p<.001$.

\section{Exploratory Analyses}

We also conducted unregistered exploratory analyses to investigate the most prominent predictors of COVID-19 conspiracy beliefs and the level of preventive measures. We performed hierarchical regression analyses in which sociodemographic factors (age, sex, perceived socioeconomic status, education, religiosity, and ideology) were entered in the first step and other candidate psychological factors (generic conspiracist beliefs, faith in intuition, cognitive reflection, impulsivity, uncertainty avoidance, and perceived risk) were entered in the second step.

For COVID-19 conspiracy beliefs, sociodemographic factors explained $7.2 \%$ of the total variance. Two significant factors were age and religiosity: Females and more religious individuals were more likely to believe in such conspiracy theories (see Table 2). Entering the psychological factors in the second step explained an additional $28 \%$ of the variance. Among these variables, cognitive reflection and perceived risk were negatively and generic conspiracist beliefs was positively associated with COVID-19 conspiracy beliefs. By far the most important predictor was generic conspiracist beliefs.

For preventive measures, sociodemographic factors explained $3.1 \%$ of the variance. None of the variables, except for sex, was individually significant (see Table 3). Female participants were more likely to take preventive measures. Entering the psychological factors explained an additional $5.7 \%$ of the variance in preventive measures. Generic conspiracist beliefs and perceived risk were positively and impulsivity was negatively related to preventive measures. Impulsivity was the strongest predictor, followed by perceived risk and sex.

Table 2 Hierarchical Regression Analysis Predicting COVID-19 Conspiracy Beliefs

\begin{tabular}{|c|c|c|c|c|c|c|c|c|}
\hline Model & & $b$ & $S E$ & $\beta$ & $t$ & $p$ & Partial & Part \\
\hline \multirow[t]{7}{*}{0} & (Intercept) & 1.697 & 0.368 & & 4.611 & $<.001$ & 0.056 & 0.054 \\
\hline & Age & 0.003 & 0.002 & 0.054 & 1.836 & 0.067 & 0.111 & 0.107 \\
\hline & Sex $(0=$ Male, $1=$ Female $)$ & 0.419 & 0.115 & 0.107 & 3.649 & $<.001$ & -0.034 & -0.033 \\
\hline & Education level & -0.050 & 0.045 & -0.034 & -1.112 & 0.266 & -0.035 & -0.034 \\
\hline & Perceived socioeconomic status & -0.040 & 0.035 & -0.034 & -1.140 & 0.254 & 0.166 & 0.162 \\
\hline & Religiosity & 0.199 & 0.036 & 0.197 & 5.520 & $<.001$ & 0.046 & 0.045 \\
\hline & Ideology & 0.092 & 0.061 & 0.055 & 1.524 & 0.128 & 0.068 & 0.055 \\
\hline \multirow[t]{13}{*}{1} & (Intercept) & -0.594 & 0.536 & & -1.109 & 0.268 & 0.053 & 0.042 \\
\hline & Age & 0.003 & 0.001 & 0.055 & 2.218 & 0.027 & -0.008 & -0.006 \\
\hline & Sex $(1=$ Male, $2=$ Female $)$ & 0.171 & 0.099 & 0.044 & 1.722 & 0.085 & -0.017 & -0.013 \\
\hline & Education level & -0.010 & 0.038 & -0.007 & -0.261 & 0.794 & 0.056 & 0.054 \\
\hline & Perceived socioeconomic status & -0.016 & 0.030 & -0.014 & -0.545 & 0.586 & 0.111 & 0.107 \\
\hline & Religiosity & 0.148 & 0.031 & 0.147 & 4.833 & $<.001$ & 0.146 & 0.119 \\
\hline & Ideology & 0.186 & 0.051 & 0.110 & 3.632 & $<.001$ & 0.110 & 0.090 \\
\hline & Generic conspiracist beliefs & 1.103 & 0.059 & 0.496 & 18.699 & $<.001$ & 0.497 & 0.461 \\
\hline & Faith in intuition & 0.044 & 0.039 & 0.029 & 1.116 & 0.265 & 0.034 & 0.027 \\
\hline & Cognitive reflection & -0.175 & 0.039 & -0.114 & -4.503 & $<.001$ & -0.137 & -0.111 \\
\hline & Impulsivity & -0.069 & 0.121 & -0.015 & -0.572 & 0.568 & -0.017 & -0.014 \\
\hline & Uncertainty avoidance & 0.098 & 0.057 & 0.044 & 1.718 & 0.086 & 0.052 & 0.042 \\
\hline & Perceived risk & -0.118 & 0.050 & -0.061 & -2.336 & 0.020 & -0.071 & -0.058 \\
\hline
\end{tabular}


Table 3 Hierarchical Regression Analysis Predicting Preventive Measures

\begin{tabular}{|c|c|c|c|c|c|c|c|c|}
\hline Model & & $b$ & $S E$ & $\beta$ & $t$ & $p$ & Partial & Part \\
\hline \multirow[t]{7}{*}{0} & (Intercept) & 6.147 & 0.123 & & 50.080 & $<.001$ & 0.013 & 0.012 \\
\hline & Age & $<0.000$ & 0.001 & 0.012 & 0.410 & 0.682 & 0.164 & 0.163 \\
\hline & Sex $(0=$ Male, $1=$ Female $)$ & 0.239 & 0.044 & 0.164 & 5.435 & $<.001$ & 0.054 & 0.053 \\
\hline & Education level & 0.030 & 0.017 & 0.055 & 1.775 & 0.076 & -0.003 & -0.003 \\
\hline & Perceived socioeconomic status & -0.001 & 0.014 & -0.003 & -0.103 & 0.918 & -0.043 & -0.042 \\
\hline & Religiosity & -0.019 & 0.014 & -0.051 & -1.397 & 0.163 & 0.015 & 0.015 \\
\hline & Ideology & 0.012 & 0.023 & 0.018 & 0.505 & 0.613 & 0.012 & 0.011 \\
\hline \multirow[t]{13}{*}{1} & (Intercept) & 5.933 & 0.233 & & 25.510 & $<.001$ & 0.141 & 0.136 \\
\hline & Age & 0.001 & 0.001 & 0.011 & 0.383 & 0.702 & 0.033 & 0.032 \\
\hline & Sex $(1=$ Male, $2=$ Female $)$ & 0.205 & 0.044 & 0.140 & 4.651 & $<.001$ & -0.008 & -0.008 \\
\hline & Education level & 0.018 & 0.017 & 0.033 & 1.089 & 0.276 & -0.062 & -0.059 \\
\hline & Perceived socioeconomic status & -0.004 & 0.013 & -0.008 & -0.269 & 0.788 & 0.039 & 0.037 \\
\hline & Religiosity & -0.028 & 0.014 & -0.073 & -2.025 & 0.043 & 0.066 & 0.063 \\
\hline & Ideology & 0.029 & 0.023 & 0.046 & 1.266 & 0.206 & 0.049 & 0.046 \\
\hline & Generic conspiracist beliefs & 0.057 & 0.026 & 0.068 & 2.167 & 0.030 & 0.030 & 0.029 \\
\hline & Faith in intuition & 0.028 & 0.018 & 0.049 & 1.590 & 0.112 & -0.173 & -0.168 \\
\hline & Cognitive reflection & 0.017 & 0.017 & 0.030 & 0.993 & 0.321 & -0.017 & -0.016 \\
\hline & Impulsivity & -0.309 & 0.054 & -0.175 & -5.757 & $<.001$ & 0.154 & 0.149 \\
\hline & Uncertainty avoidance & -0.014 & 0.025 & -0.017 & -0.541 & 0.588 & 0.013 & 0.012 \\
\hline & Perceived risk & 0.114 & 0.022 & 0.157 & 5.089 & $<.001$ & 0.164 & 0.163 \\
\hline
\end{tabular}

\section{Discussion}

We recruited a large sample from a non-WEIRD country, Turkey, to investigate the psychological correlates of belief in COVID-19 conspiracy theories and preventive measures. We found evidence for our preregistered hypotheses that higher intuitive thinking tendency (both self-reported and performance-based), impulsivity, generic conspiracy beliefs, religiosity, and right-wing ideology are associated with a higher level of belief in COVID-19 conspiracy theories. In contrast to our expectation, we failed to find any significant association between COVID-19 conspiracy beliefs and preventive measures. These findings are in line with the previous literature on the psychology of conspiracy theories (e.g., Swami et al. 2010) but not compatible with the literature linking conspiracy beliefs to the health impairing behaviors (e.g., Goreis and Voracek 2019).

Although it has been already shown that the COVID-19 is very unlikely to be a laboratory construct virus (Andersen et al. 2020), COVID-19-related conspiracy beliefs have spread rapidly (Frenkel et al. 2020). However, little is known about to what extent COVID-19 conspiracy beliefs contribute to the compliance with the preventive measures. We adopted an individual differences approach and explored this association. Although believing in conspiracy theories had been previously associated with various health impairing behaviors (Goreis and Voracek 2019), our results failed to find any evidence in Turkey. The first possibility of this null finding is that there is indeed no association between these two variables in the COVID-19 context where the risk perception is very high due to death toll unlike other health-related behaviors such as rejection of vaccination and prevention of sexually transmitted diseases. Second, there might be some boundary conditions. Plohl and Musil (2020) have recently proposed a boundary condition (trust in science) to explain this association. Another boundary condition might be the country (where the study is conducted) due to different numbers of confirmed cases and death tolls (i.e., risk perception) among the countries. Interestingly, as of April 2020, we witnessed an armed protest in Michigan, the U.S., demanding the reopening of the economy and an end to preventive measure orders on the grounds that the measures violate the right of freedom. Thus, our initial conjecture that anti-prevention attitudes during the outbreak might partially be explained by the reliance on conspiracy theories about COVID-19 might be observed in other countries such as the U.S.

There is also extensive literature indicating that deficiencies in cognitive ability and motivation of critical thinking play a role in believing conspiracy beliefs (Douglas et al. 2017). Therefore, our findings dovetail with the previous ones and show that the negative association between reliance on reflective thinking and conspiracy beliefs is stable in Turkey, a non-WEIRD country. This finding is also practically important since recent research (Orosz et al. 2016) has shown that 
rational arguments against conspiracy beliefs can be used as a nudge in reducing the endorsement of conspiracy beliefs. We also hypothesized that since reliance on intuitive thinking favors belief in conspiracy theories as shown in the previous literature (Pennycook et al. 2015; Swami et al. 2014) and the current research, reliance on intuition might also predict the level of compliance with preventive measures, yet we failed to find any association. The independent predictors of preventive measures were impulsivity and risk perception. Those who are less impulsive and perceive more risk for the COVID-19 are more likely to take preventive measures.

\section{Potential Limitations and Directions for Future Research}

One of the limitations of this study is that we used a large but a convenience sample from Turkey, which might not be representative of the Turkish population. Future research should also measure actual behaviors rather than behavioral intentions. It is of course very difficult to measure actual preventive behaviors in a research context but applications that provide data via GPS on how far people are away from their homes during the outbreak can be used as an operationalization of preventive behavior.

Another limitation would be regarding the validity of the measures. Although almost all of the measures used in the current research were previously developed and tested for their psychometric properties, there were two exceptions: Measures of COVID-19 conspiracy belief and preventive measures were developed for the current research. As COVID-19 is a novel phenomenon, there were no established measures regarding COVID-19 conspiracy beliefs by the time we conducted our research. But we did include all potentially relevant variables in our study, including generic conspiracist beliefs and several individual differences that are known to be related to conspiracy beliefs. We did not only include them in our design, but we also preregistered theory-driven hypotheses before data collection, and almost all of our hypotheses were supported. Therefore, the data are self-explanatory regarding the validity of the measure. As for the preventive measures, future research is needed to investigate its factorial structure and relationship with individual differences.

\section{Conclusion}

We have reported data on a timely issue, COVID-19, of a high-powered sample from an underrepresented, nonWEIRD population, Turkey, and conducted pre-registered theory-driven hypotheses. This study is one of the earlier studies trying to understand conspiracy beliefs and preventive behaviors in the context of the COVID-19. Overall, our findings replicated most of the associations previously found regarding the psychology of the conspiracy theories in Turkey but did not find any evidence of its association with preventive behavioral intentions in contrast to the literature linking conspiracy beliefs to health impairing behaviors. We argue that the current study paves the way for further research tapping into the predictors of health-related conspiracy theories and preventive measures, and aiming to accumulate scientific knowledge to tackle practical problems in the times of pandemics.

\section{Compliance with Ethical Standards}

Conflict of Interest On behalf of all authors, the corresponding author states that there is no conflict of interest.

Ethical Approval Ethical approval for the study was granted by the ethical board of Yasar University, Turkey (March 27, 2020; No: 3091). All participants were provided with an informed consent form before their participation.

\section{References}

Andersen, K. G., Rambaut, A., Lipkin, W. I., Holmes, E. C., \& Garry, R. F. (2020). The proximal origin of SARS-CoV-2. Nature Medicine, 26(4), 450-452. https://doi.org/10.1038/s41591-020-0820-9.

Bakhshani, N. M. (2014). Impulsivity: A predisposition toward risky behaviors. International Journal of High Risk Behaviors \& Addiction, 3(2), e20428. https://doi.org/10.5812/\%2Fijhrba.20428.

Bilewicz, M., Winiewski, M., Kofta, M., \& Wójcik, A. (2013). Harmful ideas, the structure and consequences of anti-semitic beliefs in Poland. Political Psychology, 34(6), 821-839. https://doi.org/10. 1111/pops.12024.

Bird, S. T., \& Bogart, L. M. (2005). Conspiracy beliefs about HIV/AIDS and birth control among African Americans: Implications for the prevention of HIV, other STIs, and unintended pregnancy. Journal of Social Issues, 61(1), 109-126. https://doi.org/10.1111/j.00224537.2005.00396.x

Bogart, L. M., \& Thorburn, S. (2006). Relationship of African Americans' sociodemographic characteristics to belief in conspiracies about HIV/AIDS and birth control. Journal of the National Medical Association, 98(7), 1144-1150.

Bronstein, M. V., Pennycook, G., Bear, A., Rand, D. G., \& Cannon, T. D. (2019). Belief in fake news is associated with delusionality, dogmatism, religious fundamentalism, and reduced analytic thinking. Journal of Applied Research in Memory and Cognition, 8(1), 108-117. https://doi.org/10.1016/j.jarmac.2018.09.005.

Brotherton, R., French, C. C., \& Pickering, A. D. (2013). Measuring belief in conspiracy theories: The generic conspiracist beliefs scale. Frontiers in Psychology, 4, 279. https://doi.org/10.3389/fpsyg. 2013.00279 .

Bruder, M., Haffke, P., Neave, N., Nouripanah, N., \& Imhoff, R. (2013). Measuring individual differences in generic beliefs in conspiracy theories across cultures: Conspiracy mentality questionnaire. Frontiers in Psychology, 4, 225. https://doi.org/10.3389/fpsyg. 2013.00225

Cameron, L. D., \& Diefenbach, M. A. (2001). Responses to information about psychosocial consequences of genetic testing for breast cancer susceptibility: Influences of cancer worry and risk perceptions. Journal of Health Psychology, 6(1), 47-59 10.1177\% 2F135910530100600104. 
Carleton, R. N., Norton, M. P. J., \& Asmundson, G. J. (2007). Fearing the unknown: A short version of the intolerance of uncertainty scale. Journal of Anxiety Disorders, 21(1), 105-117. https://doi.org/10. 1016/j.janxdis.2006.03.014.

Douglas, K. M., \& Sutton, R. M. (2004). Right about others, wrong about ourselves? Actual and perceived self-other differences in resistance to persuasion. British Journal of Social Psychology, 43(4), 585-603. https://doi.org/10.1348/0144666042565416.

Douglas, K. M., \& Sutton, R. M. (2015). Climate change: Why the conspiracy theories are dangerous. Bulletin of the Atomic Scientists, 71(2), 98-106. https://doi.org/10.1177/0096340215571908.

Douglas, K. M., \& Sutton, R. M. (2018). Why conspiracy theories matter: A social psychological analysis. European Review of Social Psychology, 29(1), 256-298. https://doi.org/10.1080/10463283. 2018.1537428.

Douglas, K. M., Sutton, R. M., Callan, M. J., Dawtry, R. J., \& Harvey, A. J. (2016). Someone is pulling the strings: Hypersensitive agency detection and belief in conspiracy theories. Thinking \& Reasoning, 22(1), 57-77. https://doi.org/10.1080/13546783.2015.1051586.

Douglas, K. M., Sutton, R. M., \& Cichocka, A. (2017). The psychology of conspiracy theories. Current Directions in Psychological Science, 26(6), 538-542. https://doi.org/10.1177/0963721417718261.

Franks, B., Bangerter, A., \& Bauer, M. (2013). Conspiracy theories as quasi-religious mentality: An integrated account from cognitive science, social representations theory, and frame theory. Frontiers in Psychology, 4, 424. https://doi.org/10.3389/fpsyg.2013.00424.

Frederick, S. (2005). Cognitive reflection and decision making. Journal of Economic Perspectives, 19(4), 25-42. https://doi.org/10.1257/ 089533005775196732 .

Frenkel, S., Alba, D., \& Zhong, R. (2020, March 8). Surge of virus misinformation stumps facebook and twitter. The New York Times. https://www.nytimes.com/2020/03/08/technology/ coronavirus-misinformation-socialmedia.html

Gaston, G. B., \& Alleyne-Green, B. (2013). The impact of African Americans' beliefs about HIV medical care on treatment adherence: A systematic review and recommendations for interventions. AIDS and Behavior, 17(1), 31-40. https://doi.org/10.1007/ s10461-012-0323-x.

Goreis, A., \& Voracek, M. (2019). A systematic review and metaanalysis of psychological research on conspiracy beliefs: Field characteristics, measurement instruments, and associations with personality traits. Frontiers in Psychology, 10, 205. https://doi.org/10. 3389/fpsyg.2019.00205.

Granö, N., Virtanen, M., Vahtera, J., Elovainio, M., \& Kivimäki, M. (2004). Impulsivity as a predictor of smoking and alcohol consumption. Personality and Individual Differences, 37(8), 1693-1700. https://doi.org/10.1016/j.paid.2004.03.004.

Güleç, H., Tamam, L., Turhan, M., Karakuș, G., Zengin, M., \& Stanford, M. S. (2008). Psychometric properties of the Turkish version of the Barratt impulsiveness Scale-11. Klinik Psikofarmakoloji Bulteni, 18(4).

Harper, C. A., Satchell, L., Fido, D., \& Latzman, R. (2020, April 1). Functional fear predicts public health compliance in the COVID19 pandemic. https://doi.org/10.31234/osf.io/jkfu3

Henrich, J., Heine, S. J., \& Norenzayan, A. (2010). Most people are not WEIRD. Nature, 466(7302), 29.

Imhoff, R., \& Bruder, M. (2014). Speaking (un-) truth to power: Conspiracy mentality as a generalised political attitude. European Journal of Personality, 28(1), 25-43. https://doi.org/ 10.1002/per.1930.

Jolley, D., \& Douglas, K. M. (2014). The effects of anti-vaccine conspiracy theories on vaccination intentions. PLoS One, 9(2), e89177. https://doi.org/10.1371/journal.pone.0089177.

Jolley, D., Douglas, K. M., Leite, A. C., \& Schrader, T. (2019). Belief in conspiracy theories and intentions to engage in everyday crime.
British Journal of Social Psychology, 58(3), 534-549. https://doi. org/10.1111/bjso.12311.

Jolley, D., Meleady, R., \& Douglas, K. M. (2020). Exposure to intergroup conspiracy theories promotes prejudice which spreads across groups. British Journal of Psychology, 111(1), 17-35. https://doi. org/10.1111/bjop.12385.

Jost, J. T., Ledgerwood, A., \& Hardin, C. D. (2008). Shared reality, system justification, and the relational basis of ideological beliefs. Social and Personality Psychology Compass, 2(1), 171-186. https:// doi.org/10.1111/j.1751-9004.2007.00056.x.

Leman, P. J., \& Cinnirella, M. (2013). Beliefs in conspiracy theories and the need for cognitive closure. Frontiers in Psychology, 4, 378. https://doi.org/10.3389/fpsyg.2013.00378.

Leung, G. M., Quah, S., Ho, L. M., Ho, S. Y., Hedley, A. J., Lee, H. P., \& Lam, T. H. (2004). A tale of two cities: Community psychobehavioral surveillance and related impact on outbreak control in Hong Kong and Singapore during the severe acute respiratory syndrome epidemic. Infection Control \& Hospital Epidemiology, 25(12), 1033-1041. https://doi.org/10.1086/502340.

Lewandowsky, S., Gignac, G. E., \& Oberauer, K. (2013). The role of conspiracist ideation and worldviews in predicting rejection of science. PLoS One, 8(10), e75637. https://doi.org/10.1371/journal. pone. 0075637 .

Marchlewska, M., Cichocka, A., \& Kossowska, M. (2018). Addicted to answers: Need for cognitive closure and the endorsement of conspiracy beliefs. European Journal of Social Psychology, 48(2), 109117. https://doi.org/10.1002/ejsp.2308.

McCaul, K. D., Canevello, A. B., Mathwig, J. L., \& Klein, W. M. P. (2003). Risk communication and worry about breast cancer. Psychology, Health \& Medicine, 8(4), 379-389. https://doi.org/10. 1080/13548500310001604513.

Newheiser, A. K., Farias, M., \& Tausch, N. (2011). The functional nature of conspiracy beliefs: Examining the underpinnings of belief in the Da Vinci code conspiracy. Personality and Individual Differences, 51(8), 1007-1011. https://doi.org/10.1016/j.paid.2011.08.011.

Oh, S. H., Lee, S. Y., \& Han, C. (2020). The Effects Of Social Media Use On Preventive Behaviors During Infectious Disease Outbreaks: The Mediating Role of Self-relevant Emotions and Public Risk Perception. In Health Communication. https://doi.org/10.1080/ 10410236.2020.1724639.

Oliver, J. E., \& Wood, T. (2014). Medical conspiracy theories and health behaviors in the United States. JAMA Internal Medicine, 174(5), 817-818. https://doi.org/10.1001/jamainternmed.2014.190.

Orosz, G., Krekó, P., Paskuj, B., Tóth-Király, I., Bőthe, B., \& RolandLévy, C. (2016). Changing conspiracy beliefs through rationality and ridiculing. Frontiers in Psychology, 7, 1525. https://doi.org/ 10.3389/fpsyg.2016.01525.

Pacini, R., \& Epstein, S. (1999). The relation of rational and experiential information processing styles to personality, basic beliefs, and the ratio-bias phenomenon. Journal of Personality and Social Psychology, 76(6), 972-987. https://doi.org/10.1037/0022-3514. 76.6.972.

Pasek, J., Stark, T. H., Krosnick, J. A., \& Tompson, T. (2015). What motivates a conspiracy theory? Birther beliefs, partisanship, liberal-conservative ideology, and anti-black attitudes. Electoral Studies, 40, 482-489. https://doi.org/10.1016/j.electstud.2014.09. 009.

Patton, J. H., Stanford, M. S., \& Barratt, E. S. (1995). Factor structure of the Barratt impulsiveness scale. Journal of Clinical Psychology, 51(6), 768-774. https://doi.org/10.1002/1097-4679 (199511)51: 6\%3C768::AID-JCLP2270510607\%3E3.0.CO;2-1.

Pennycook, G., \& Rand, D. G. (2019). Lazy, not biased: Susceptibility to partisan fake news is better explained by lack of reasoning than by motivated reasoning. Cognition, 188, 39-50. https://doi.org/10. 1016/j.cognition.2018.06.011. 
Pennycook, G., Cheyne, J. A., Barr, N., Koehler, D. J., \& Fugelsang, J. A. (2015). On the reception and detection of pseudo-profound bullshit. Judgment and Decision making, 10(6), 549-563.

Plohl, N., \& Musil, B. (2020, April 6). Modeling compliance with COVID-19 prevention guidelines: The critical role of trust in science. https://doi.org/10.31234/osf.io/6a2cx

Qian, M., Wu, Q., Wu, P., Hou, Z., Liang, Y., Cowling, B. J., \& Yu, H. (2020, February 20). Psychological responses, behavioral changes and public perceptions during the early phase of the COVID-19 outbreak in China: A population based cross-sectional survey. https://doi.org/10.1101/2020.02.18.20024448.

Sarıçam, H., Erguvan, F. M., Akın, A., \& Akça, M. Ș. (2014). The Turkish short version of the intolerance of uncertainty (Ius-12) scale: The study of validity and reliability. Route Educational and Social Science Journal, 1(3), 148-157.

Stanley, M., Barr, N., Peters, K., \& Seli, P. (2020, March 30). Analyticthinking predicts hoax beliefs and helping behaviors in response to the COVID-19 pandemic. https://doi.org/10.31234/osf.io/m3vth

Swami, V. (2012). Social psychological origins of conspiracy theories: The case of the Jewish conspiracy theory in Malaysia. Frontiers in Psychology, 3, 280. https://doi.org/10.3389/fpsyg.2012.00280.

Swami, V., \& Furnham, A. (2014). Political paranoia and conspiracy theories. In J.-P. Prooijen \& P. A. M. van Lange (Eds.), Power politics, and paranoia: Why people are suspicious of their leaders (pp. 218-236). Cambridge: Cambridge University Press.

Swami, V., Chamorro-Premuzic, T., \& Furnham, A. (2010). Unanswered questions: A preliminary investigation of personality and individual difference predictors of 9/11 conspiracist beliefs. Applied Cognitive Psychology, 24(6), 749-761. https://doi.org/10.1002/acp.1583.

Swami, V., Nader, I. W., Pietschnig, J., Stieger, S., Tran, U. S., \& Voracek, M. (2012). Personality and individual difference correlates of attitudes toward human rights and civil liberties. Personality and Individual Differences, 53(4), 443-447. https://doi.org/10.1016/j. paid.2012.04.015.

Swami, V., Voracek, M., Stieger, S., Tran, U. S., \& Furnham, A. (2014). Analytic thinking reduces belief in conspiracy theories. Cognition, 133(3), 572-585. https://doi.org/10.1016/j.cognition.2014.08.006.

Swami, V., Furnham, A., Smyth, N., Weis, L., Lay, A., \& Clow, A. (2016). Putting the stress on conspiracy theories: Examining associations between psychological stress, anxiety, and belief in conspiracy theories. Personality and Individual Differences, 99, 72-76. https://doi.org/10.1016/j.paid.2016.04.084.
Türk, E. G., \& Artar, M. (2014). Adaptation of the rational experiential inventory: Study of reliability and validity. Journal of Faculty of Educational Sciences, 47(1).

van Harreveld, F., Rutjens, B. T., Schneider, I. K., Nohlen, H. U., \& Keskinis, K. (2014). In doubt and disorderly: Ambivalence promotes compensatory perceptions of order. Journal of Experimental Psychology: General, 143(4), 1666-1676. https://doi.org/10.1037/ a0036099.

van Prooijen, J. W., \& de Vries, R. E. (2016). Organizational conspiracy beliefs: Implications for leadership styles and employee outcomes. Journal of Business and Psychology, 31(4), 479-491. https://doi. org/10.1007/s10869-015-9428-3.

van Prooijen, J. W., \& Jostmann, N. B. (2013). Belief in conspiracy theories: The influence of uncertainty and perceived morality. European Journal of Social Psychology, 43(1), 109-115. https:// doi.org/10.1002/ejsp.1922.

van Prooijen, J. W., \& van Dijk, E. (2014). When consequence size predicts belief in conspiracy theories: The moderating role of perspective taking. Journal of Experimental Social Psychology, 55, 6373. https://doi.org/10.1016/j.jesp.2014.06.006.

Whitson, J. A., \& Galinsky, A. D. (2008). Lacking control increases illusory pattern perception. Science, 322(5898), 115-117. https:// doi.org/10.1126/science.1159845.

Wood, M. J., Douglas, K. M., \& Sutton, R. M. (2012). Dead and alive: Beliefs in contradictory conspiracy theories. Social Psychological and Personality Science, 3(6), 767-773 10.1177\% 2F1948550611434786.

World Health Organization. (2020a). Coronavirus disease 2019 (COVID19) situation report (Report No. 87). https://www.who.int/docs/ default-source/coronaviruse/situation-reports/20200416-sitrep-87covid-19.pdf?sfvrsn=9523115a_2

World Health Organization. (2020b). Coronavirus disease (COVID-19) advice for the public. https://www.who.int/emergencies/diseases/ novel-coronavirus-2019/advice-for-public

Yilmaz, O., \& Saribay, S. A. (2016). An attempt to clarify the link between cognitive style and political ideology: A non-western replication and extension. Judgment and Decision making, 11(3), 287-300.

Publisher's Note Springer Nature remains neutral with regard to jurisdictional claims in published maps and institutional affiliations. 